\title{
Effect of open space surface treatment and built form on thermal profile: A case of Mumbai, India
}

\author{
Surabhi Mehrotra1, Maulana Azad National Institute of Technology, Bhopal (India) \\ Divya Subramanian, Indian Institute of Technology Bombay, Mumbai (India) \\ Ronita Bardhan, Indian Institute of Technology Bombay, Mumbai (India) \\ Arnab Jana, Indian Institute of Technology Bombay, Mumbai (India)
}

\begin{abstract}
The thermal environment in of Recreational Open Spaces (ROS) is primarily a result of the surrounding built form which includes buildings, trees, and surface treatment materials. To study the impact of land surface treatment choice and urban form on the thermal characteristics of open spaces, a case study assessment was undertaken in the dense urban context of Mumbai, India. To study ROS and its thermal profile, we selected three open spaces adjoining a school in Mumbai exhibiting different surface material treatments and built form. A comparative analysis was completed using ENVI-met based modelling. The model outcomes were validated using heat stress meters and thermal infrared camera readings.

The results highlighted the significant impact of the land surface choice and vegetation on the ambient air temperature and surface temperature of ROS. Open spaces with concrete paving and open mud surface showed the air temperature about $3^{\circ} \mathrm{C}$ and $1.5^{\circ} \mathrm{C}$ higher than the surfaces covered with natural materials during day hours. During the evening, concrete surfaces showed comparatively high maximum surface temperatures (Ts) compared to other, i.e. by 4.1 ${ }^{\circ} \mathrm{C}$. The inferences from this study would assist in appropriate policy formation and design guidelines that render thermally suitable ROS and mitigate the urban heat island effect.
\end{abstract}

\footnotetext{
${ }^{1}$ Corresponding Author: surabhimehrotra@gmail.com
} 
Keywords

30 Recreational Open Spaces; Urban Heat Island; Surface Treatment; Thermal Comfort;

31 Developing Nations

32

33 Nomenclature

$\begin{array}{ll}\text { ROS } & \text { Recreational Open Space } \\ \text { Ta } & \text { Ambient Air Temperature } \\ \text { Ts } & \text { Surface Temperature } \\ \text { V } & \text { Wind speed } \\ \text { hrs } & \text { Hours }\end{array}$

\section{$35 \quad 1.0$ Introduction}

Recreational amenities like parks and playgrounds are essential natural spaces in the

37 dense urban context that help to improve the urban quality of life (Tian et al., 2014). ROS help in

38 mitigating various urbanization ills by providing many ecosystem services like improving and

39 sustaining varied biodiversity, aiding stormwater management, improving air quality, and carbon

40 sequestration (Konijnendijk et al., 2013). Various studies have investigated the cooling effects of

41 open space entities like vegetation and natural surface treatment through processes like

42 evapotranspiration (Bolund and Hunhammar, 1999; Bowler et al., 2010; Zhang et al., 2014),

43 cooling of air from shading provided by trees, etc. (Chang and Li, 2014; Georgi and Zafiriadis,

44 2006; Lin et al., 2015; Mcpherson et al., 1997). Dense urban areas are experiencing increased air

45 temperatures owing to climate change that negatively impacts human comfort and health

46 (Spronken-Smith and Oke, 1998). With the increasing trends of land surface temperature in

47 urban areas, the thermal profile in ROS are worst affected (Liu et al., 2017; Sodoudi et al., 2018).

48 The thermal profile of ROS is primarily a result of the surrounding built form that includes

49 buildings, trees, and the surface treatment material. Inappropriately planned ROS could 
50 adversely affect their thermal profile, resulting in underperforming or underutilized civic 51 amenities.

52 Studies that investigate thermal profile in open spaces, usually consider air temperature, solar 53 radiation, and wind speed (Givoni et al., 2003). Certain studies look at the design of the open 54 space or the built environment surrounding the open space to evaluate the thermal comfort for 55 the ROS (Martinelli et al., 2014). The study by Cohen et.al. (Cohen et al., 2014) further 56 investigated the environment quality associated with open spaces emphasizing on the in-situ 57 measurements of pertinent indices of noise and air pollution along with certain climatic 58 variables. Furthermore, land surface treatment and surrounding form for open spaces was 59 investigated to be major influencers affecting the experienced thermal comfort (Chatzidimitriou 60 and Yannas, 2015).

61 Past studies have used existing thermal indices like Physiological Equivalent Temperature 62 (PET), Universal Thermal Climate Index (UTCI) for investigating the thermal profile of open 63 spaces (Golasi et al., 2018; Höppe, 1999; Mehrotra et al., 2020). However, given the number of 64 indices, the selection of appropriate indices and its validation is difficult. Also, a particular Index 65 does not capture the actual ground condition completely. To analyse thermal comfort in open 66 spaces, microscale studies have been conducted using computational models that model various 67 scenarios. Once validated, results of computation models provide basis for proposing 68 implementing statergies for heat mitigation (Crank et al., 2018). Outdoor thermal profile studies 69 are needed to suggest mitigation statergies like cool roof, green cover, cool pavements in open 70 spaces (Akbari and Kolokotsa, 2016; Erell and Pearlmutter, 2012; Taleghani, 2018). Numerical 71 models like ENVI-met and SOLWEIG are widely in modelling thermal variables for various 72 regions (Acero and Herranz-Pascual, 2015; Emmanuel et al., 2007; Lindberg et al., 2016; 73 Mehrotra et al., 2019).

74 Few studies have assessed the linkage between built form, open spaces, and the resultant 75 thermal profile, specifically for the context of a developing nation. The current study is an 76 attempt to corroborate the effect of varied surface treatments and surrounding built forms on the 77 thermal profile of open spaces specific to the urban context of Mumbai, India. Due to robust and 
accurate capability to model complex outdoor environment (Salata et al., 2016; Wu and Chen,

79 2017), ENVI-met is used to carry out this study.

Mumbai is a densely populated tropical megacity of India. This coastal city has a high level of humidity with moderately hot temperatures throughout the year. The city 82 experiences three seasons of summer, monsoon, and winter. The city experiences three 83 seasons of summers (March to May), winter (October to February) and monsoon (June to 84 September). Past weather data of Mumbai (year 1981-2010) from the India Meteorological 85 Department (IMD) archives for santacruz station, show that city's average maximum 86 temperature as $37.60 \mathrm{C}$ in summers with average minimum of $14.3 \mathrm{oC}$ in Winters. Highest 87 temperature of 42.2 is recorded in the month of April. Average precipitation is 2,184. mm and average humidity as $74 \%$. The available green open spaces in Mumbai is about 0.8 sq.m. per capita, much lower than the WHO recommended standard of 9 sq.m. per capita (MMR-EIS, 2012). There is a scarcity of available and usable open spaces in Mumbai for the vast population. To ensure better comfort for open space users, the ROS must be planned to optimize their thermal profile. To understand the impact of land surface treatment choice and urban form, on the ambient air temperature and the resultant thermal comfort, a case study assessment was undertaken. To study ROS and its thermal profile, a selection of three open spaces adjoining a school in Mumbai within the IIT Bombay campus was made. IIT Bombay is an educational institution and campus located in the ' $S$ ' ward jurisdiction of Mumbai metropolitan area. The selected ROS surfaces were treated with different materials and were around different built forms. The surrounding included the presence of trees and built forms of different heights and types. Figure 1 represents the location of three case study sites within the IIT Bombay campus and depicts the varied built form and land surface treatments of the respective sites. The land surface materials were earth/mud, concrete, paver tiles, and asphalt. ENVI-met modelling was used with further validation methods to quantify and validate the variation in the thermal profile of open spaces as explained in the following section. 


\begin{tabular}{|c|c|c|c|c|c|}
\hline $\begin{array}{l}\text { Sr. } \\
\text { No. }\end{array}$ & $\begin{array}{l}\text { Monitoring } \\
\text { Location }\end{array}$ & Nomenclature & $\begin{array}{l}\text { Land surface } \\
\text { Material }\end{array}$ & $\begin{array}{l}\text { Vegetation } \\
\text { Layout }\end{array}$ & $\begin{array}{l}\text { Surrounding built } \\
\text { form / Level of } \\
\text { enclosure }\end{array}$ \\
\hline 1 & KV Playground & ROS 1 & Barren soil & $\begin{array}{l}\text { Trees on the } \\
\text { outer periphery }\end{array}$ & Open \\
\hline 2 & $\begin{array}{l}\text { KV Assembly } \\
\text { Court }\end{array}$ & ROS 2 & $\begin{array}{l}\text { Concrete } \\
\text { paved floor }\end{array}$ & $\begin{array}{l}\text { Interspersed } \\
\text { trees }\end{array}$ & $\begin{array}{l}\text { Built on three } \\
\text { sides, open on } \\
\text { one end }\end{array}$ \\
\hline 3 & $\begin{array}{l}\text { Academic block } \\
\text { ground }\end{array}$ & ROS 3 & $\begin{array}{l}\text { Earth with } \\
\text { leaves on the } \\
\text { ground }\end{array}$ & Dense tree cover & $\begin{array}{l}\text { Built on one side, } \\
\text { Semi open }\end{array}$ \\
\hline
\end{tabular}

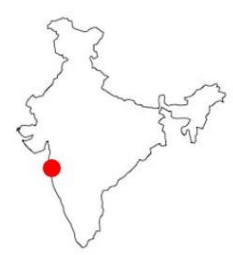

Mumbai, India

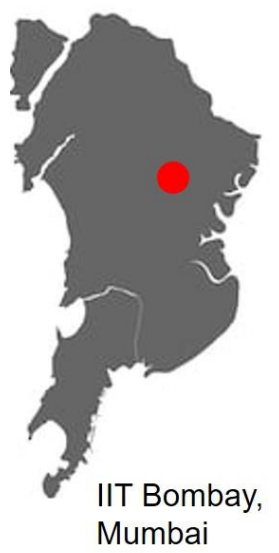

Mumbai
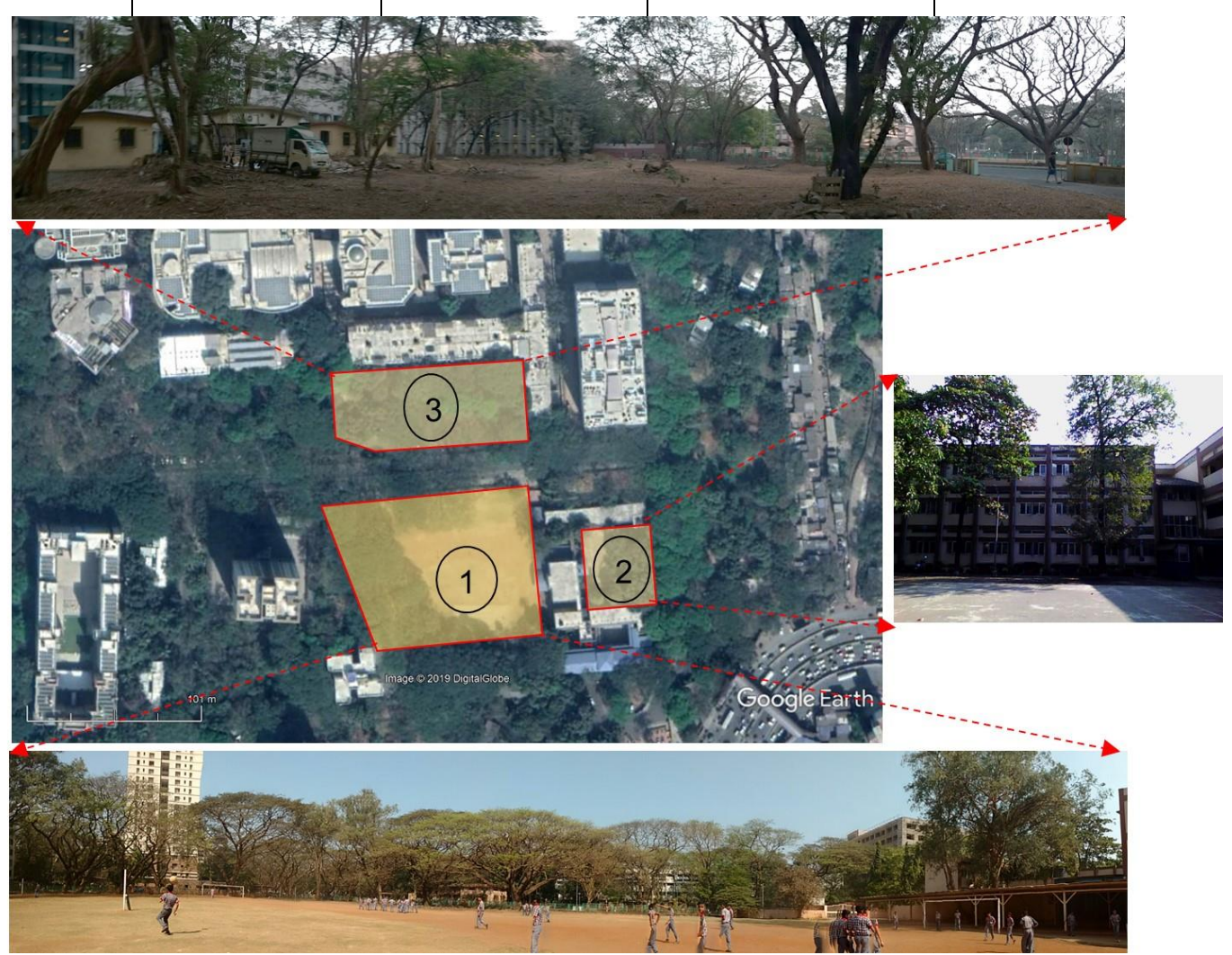

Figure 1 Case study location within the IIT Bombay campus with reference images of the context 


\section{Methodology}

A model of three ROS including built, vegetation and surface materials is prepared as an

110 input to the ENVI-met software to simulate thermal variables like air temperature and land 111 surface temperature. ENVI-met is a three-dimensional microclimate model that can simulate

112 thermal variables in urban areas with a high resolution. The ENVI-met generated output is

113 further used for comparatively analyzing the impact of land surface treatment on the ambient air

114 temperature, surface temperature, and relative thermal comfort. The results were validated using

115 ambient air temperature and surface temperature, recorded over three intervals in morning,

116 afternoon and evening, over three days. Along with the ambient air temperature readings,

117 infrared thermal imaging data of the various surface treatments were also recorded and the 118 results validated.

119 The study has three components:

126 Based on the above study components, the thermal profile of open spaces could be assessed and further to it heat mitigation measures could be suggested.

1. Simulation of three different ROS in ENVI-met

2. Monitoring of surface temperature using Infrared Camera for three different periods.

3. Monitoring of ambient air temperature using LSI heat stress meter for three different periods.

130 The simulation of the study area that included three ROS and built form elements like buildings, 131 trees, ground surface and roads were carried out in ENVI-met 4.4 winter release version. The 132 area was simulated for 12 hours for March month and validated for the same days. The input to 133 S/W includes- building footprint with height information, material finish information and its 134 insulating properties. Trees were chosen from the available library of ENVI-met as dense and 135 medium in foliage and $15 \mathrm{~m}$ to $25 \mathrm{~m}$ in height. Mumbai meterological station data was used to 
136 force ENVI-met simulations. Hourly data on Air temperature and humidity was considered while 137 wind speed and direction were kept constant. The thermal conditions were simulated from 9:00 138 am to 21:00 hours, i.e. for 12 hours for $24^{\text {th }}$ March 2017. Figure 2 shows three ROS in the study 139 area and weather profile input for ENVI-met simulations.

140

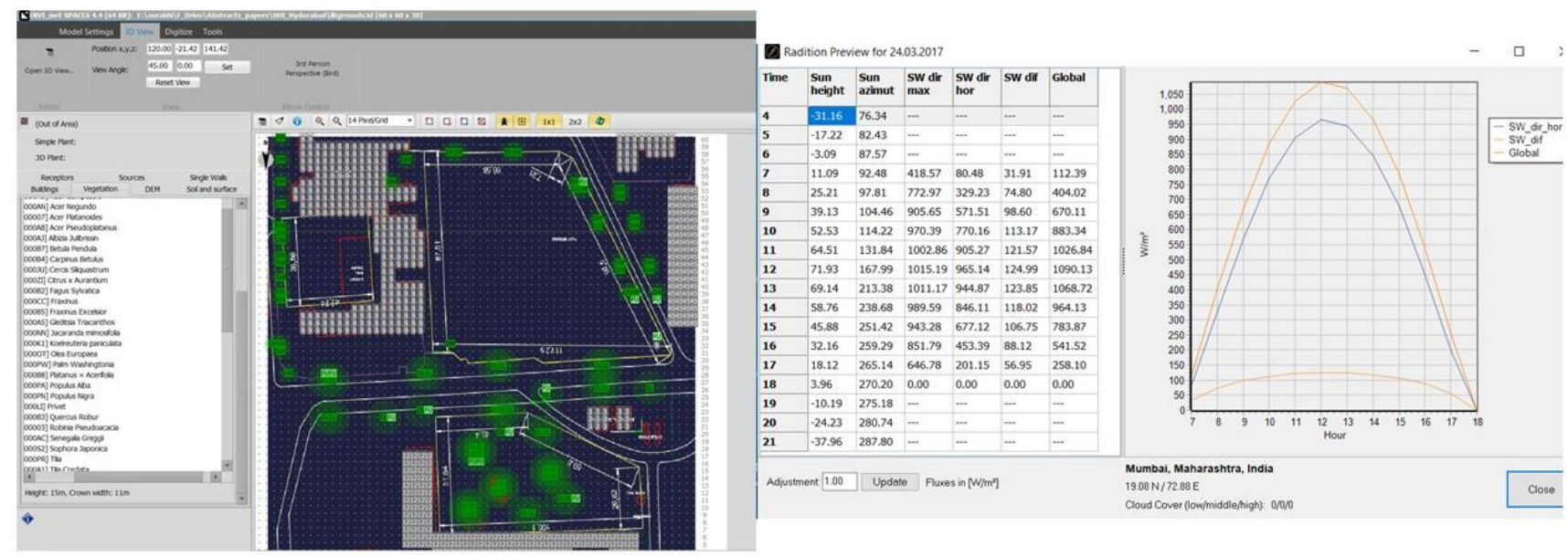

Figure 2: Input area and meteorological data files in ENVI-met for simulations

\section{$143 \quad 2.2$ Monitoring Surface Temperature (Ts)}

144 The study area simulated for air temperature (Ta), wind flow (v) and surface temperature (Ts).

145 The results from ENVI-met simulations are verified on the ground on for three times in a day for 146 a week duration. The verification is carried out using FLIR E60 Thermal Imaging camera, that 147 captures the radiated heat from the surfaces. The difference in Ts of three ROS is captured by the 148 camera. The emissivity ranges between 0.92 to 0.95 (Chatzidimitriou and Yannas, 2015), and 149 here it is considered as 0.95 .

\section{$151 \quad 2.3$ Ambient Air temperature monitoring}

152 The simulated air temperature is verified on the field using thermal sensors - LASTEM LSI heat 153 stress meter. The instrument is commonly used to monitor outdoor thermal variables and 
154 calculate heat stress (Noro et al., 2015). Figure 3 shows the use of LSI meter for monitoring Ta 155 and Handheld FLIR Infrared camera for monitoring.

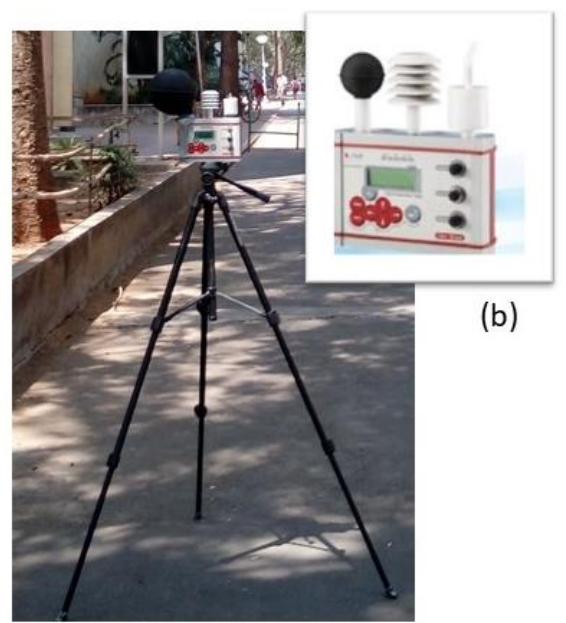

(a)

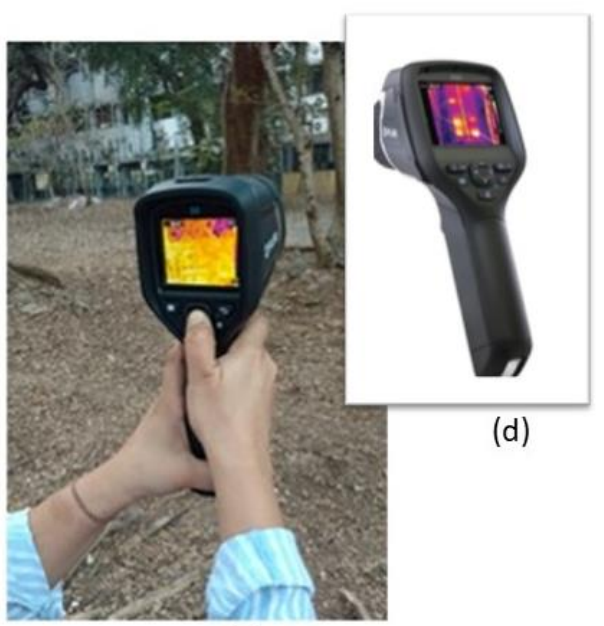

(c)

Figure 3 (a) and (b) LSI LASTEM heat stress meter, (c) and (d) Handheld FLIR thermal camera

\subsection{Results}

The study results are discussed stepwise for thermal comfort variables Ts and Ta. ENVI-

164 met model is evaluated using field measurements carried out at three selected ROS sites, during 165 three time periods of a day i.e., 11:00, 14:00 hours and 18:00 hours. Surface Temperature results 166 for three time periods for three ROS are shown in Figure 4. The apparent surface temperature 167 was accurately captured in FLIR than ENVI-met model, but results are correlated with the 168 model. Results show highest surface temperatures were found on ROS $2\left(\mathrm{Ts}=42^{\circ} \mathrm{C}\right)$ during the 169 afternoon, which could be due to direct and high solar radiation on the paved surface that emitted 170 radioactive heat. ROS 1 also found to have high Ts i.e. above $37^{\circ} \mathrm{C}$ in the afternoon (Refer 171 Figure 5) 


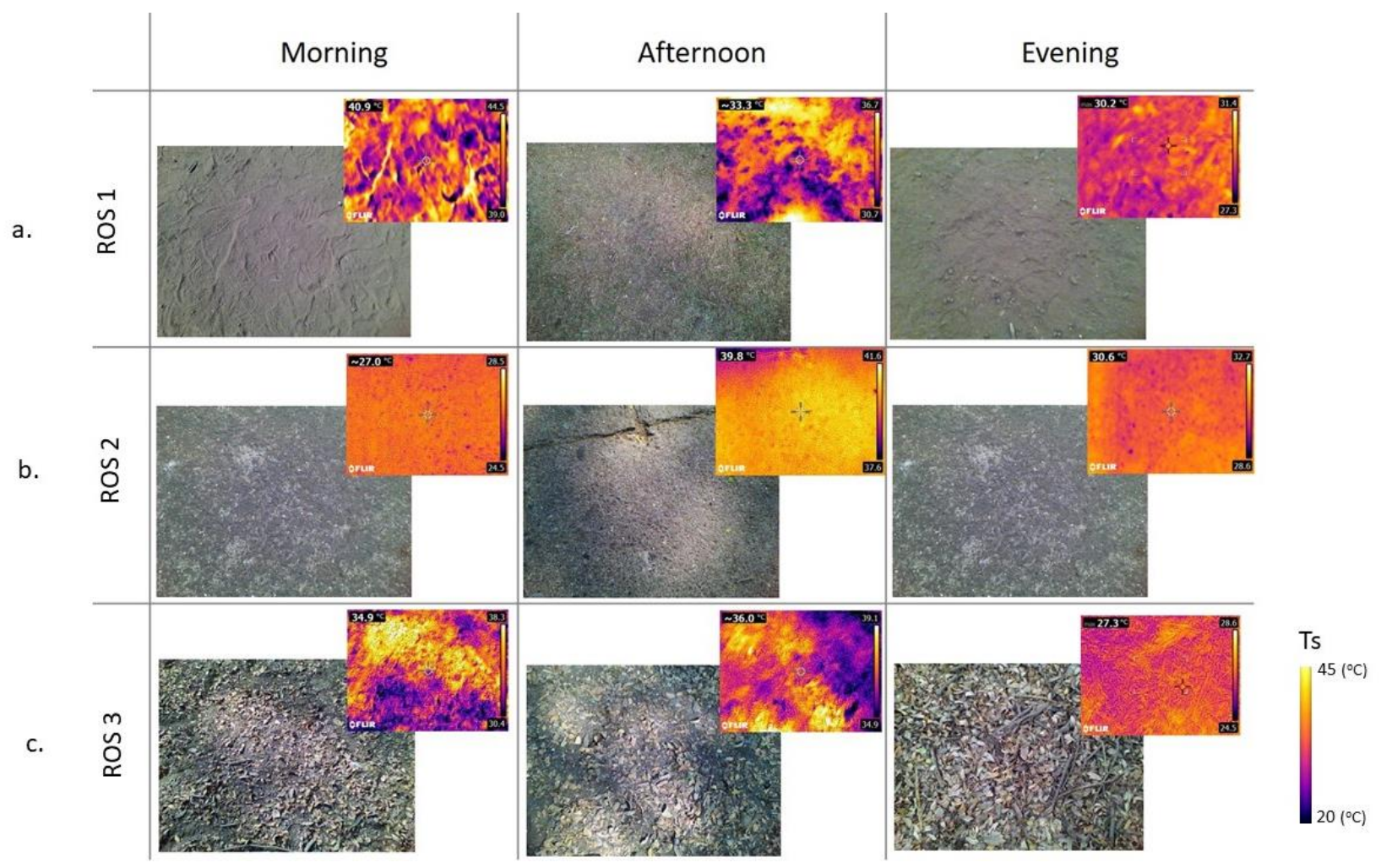

Figure 4 FLIR images of three sites showing surface temperature with the varied surface treatment a) mud cover, b) cement concrete paved and c) leaves, taken at three time of day i.e. in morning, afternoon and evening.

The field results of air temperatures correlated with the output received from ENVI-met 178 model. However, during the afternoon period, the modelled data showed higher Ta values $179\left(1.5^{\circ} \mathrm{C}\right)$ than observed Ta on-site and during evening average difference was $0.5^{\circ} \mathrm{C}$ (refer Figure 180 5). The mean error between simulations and real monitoring data was tested using the statistical 181 method Coefficient of Variance in Root mean Square Error (CVRMSE) and found to be under 182 acceptable limits i.e. CV(RMSE) is below 10\%, as per ASHRAE².

\footnotetext{
${ }^{2}$ ASHRAE - American Society of Heating, Refrigerating and Air-Conditioning Engineers publishes a set of standards and guidelines relating to thermal environmental conditions for human occupancy
} 
183
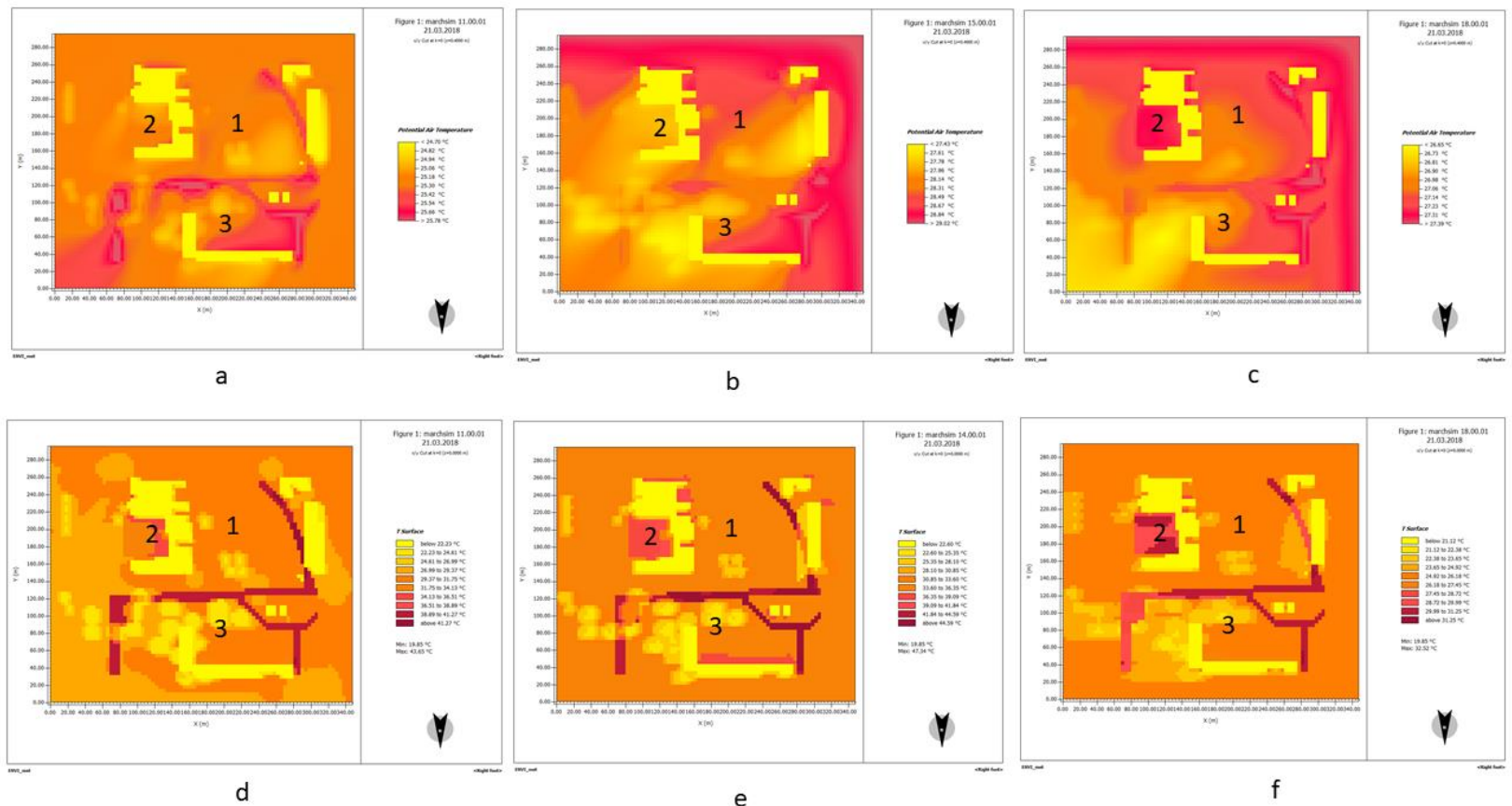

184

185 Figure $5 \mathrm{Ta}$ is modelled for three period as $\mathrm{a}, \mathrm{b}$, and $\mathrm{c}$ and Ts is modelled as $\mathrm{d}$, e and $\mathrm{f}$ for three time 186 periods, i.e. $11 \mathrm{hrs}, 14 \mathrm{hrs}$ and $18 \mathrm{hrs}$ respectively, using ENVI-met for 3 ROS in the study area.
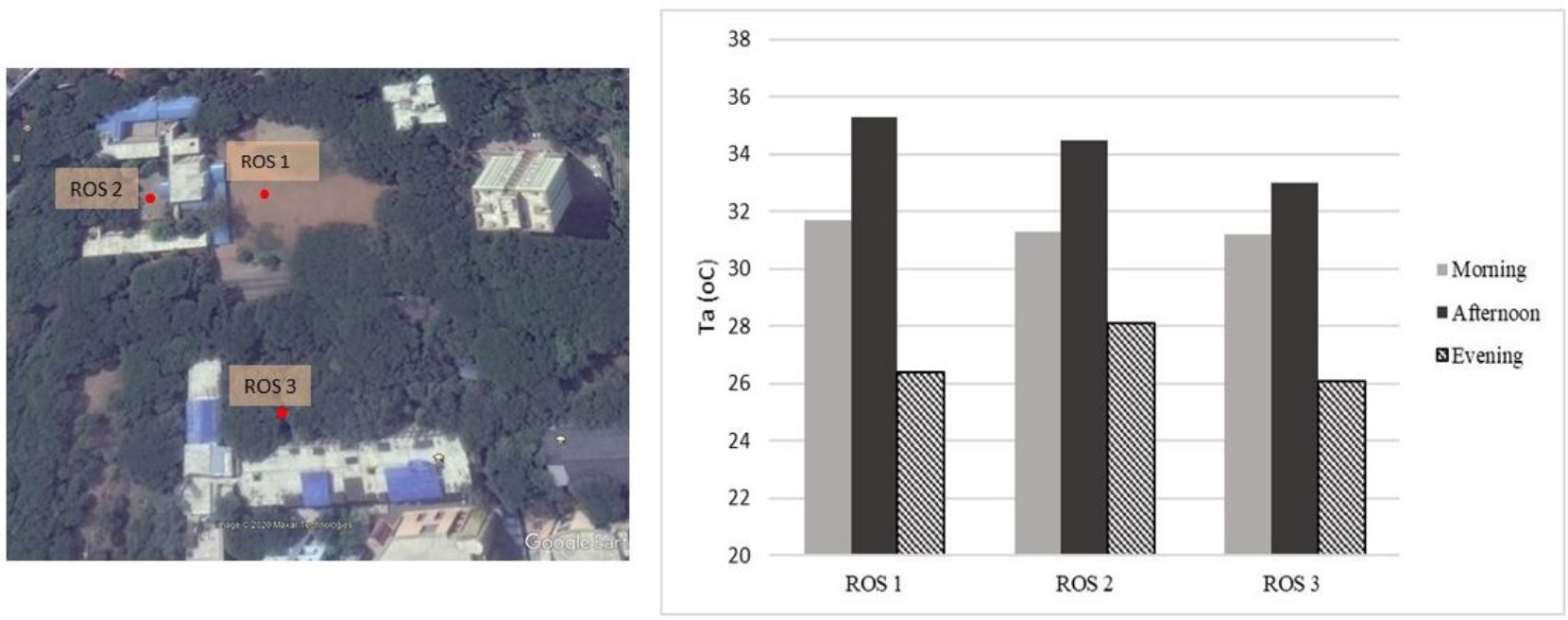

188 


\section{Discussion}

The study results indicate that built form and surface material are major parameters that

192 determine the outdoor thermal comfort of open spaces. This has implications on walkability, use

193 of open spaces as well as indoor energy usage.

194 The results show that ROS 1 and ROS 2, both have high Ta in the afternoon, but ROS 2 has 195 maximum Ta when compared to other ROS during the evening, i.e at 18:00 hours. This is the 196 time when the land surface starts cooling. The probable reason for high Ta at ROS 2 could be

197 because of the concrete paved surface that radiates heat and the surrounding built form that 198 further confines the radiant heat, raising the air temperature. The enclosure of the open space 199 should be such that it shades the ground during day time but allows heat to escape. Airflow to the 200 open space also plays an important role in dissipating the heat away.

201 ROS 1 experiences high Ta in the afternoon due to direct solar radiation that heats the exposed 202 surface. But interestingly, due to openness and airflow, the surface cools down fast, as shown in 203 Figure 6. Compared to other ROS, ROS 3 shows lower Ta and well as Ts, due to natural surface 204 cover and tree shade that lowered the surface temperature and its air temperature throughout the 205 day.

206 When surface temperature is high, its adjoining air also gets heated up due to convection. 207 Further, the built environment plays an important role in shading the surfaces as well as allowing 208 air movement to reduce heat retention - that leads to the formation of heat islands.

209 The results highlighted the significant impact of the land surface choice on the ambient 210 air temperature of recreational open spaces. Open spaces which were treated with only earth/mud 211 showed the highest air temperature $\left(\sim 34^{\circ} \mathrm{C}\right)$ and about $3^{\circ} \mathrm{C}$ higher than other areas. The air 212 temperature and surface temperature calculated using ENVI-met vary between morning, 213 afternoon and evening, where afternoon temperatures were beyond the comfortable temperature 214 range. The ground (ROS 3) enclosed with walls and trees had the most suitable thermal comfort 215 throughout the day compared to other areas. The study shows how built areas with vegetation 216 and suitable surface treatment can regulate thermal comfort in open spaces that in turn reduces 
217 the formation of urban heat islands. ENVI-met can be an effective tool in generating scenarios 218 for modulating air and surface temperatures.

219 The study indicates ENVI-met has been able to model the outdoor thermal environment

220 with acceptable accuracy. However, It has limited capability to model exact surfaces present in 221 the real-world situation. During the afternoon, the error in the model was highest and showed 222 higher values than the observed values. This could be because of not considering the shadow of 223 buildings and air flows at local levels. Another limitation of ENVI-met is that the approximation 224 of building as blocks which could affect the accuracy in estimating thermal variations. Overall, 225 the model is useful in estimating thermal parameters at different periods at a fair resolution of 226 building blocks, which is not available in other models.

227 Thus, the study brings into light how surface temperature, surrounding trees and its built 228 environment are both important to determine the thermal comfort of ROS. We can hereby 229 confirm our hypothesis based on the survey results as follows:

Policy decisions should be made considering the above parameters to provide a thermally 234 conducive open space for enhancing public usage of open spaces. The study would assist in 235 decision making pertaining to the design of building forms that render thermally suitable ROS 236 and mitigate the urban heat island effect. Using the inferences from this study, design guidelines 237 regarding the appropriate land surface treatment of ROS could also be recommended to achieve 238 thermally comfortable urban amenities of recreation. Heat mitigation measures like cool paving 239 and increasing shading devices, vegetation cover etc. Cool paving in open spaces could be 240 achieved by using high-albedo materials. Local agencies and researchers should further test these 241 materials and proposed guidelines for usage in open spaces as a mitigation measure to control 242 heat and ensure thermal comfort of users.

243 Further scope of the study includes investigation of seasonal variations in ROS types and 244 sensitivity analysis of build form parameters. 


\section{Conclusions}

246 The results of investigations of three different ROS confirms that the significant variation in

247 thermal performance of ROS is dependable on built form, surface treatment and tree cover. The 248 three open spaces behaved differently during the different time of the day. The difference was 249 maximum during the afternoon period given the influence of solar radiation on the ground. The 250 study showed the effectiveness of tree cover in regulating surface temperature and air 251 temperatures in any area. It is an effective, easily applicable and cost-effective solution to reduce

252 afternoon heat gain. Tree cover should be encouraged in all public open spaces and roads as a 253 mandatory feature, specifically in a tropical city like Mumbai that has high pedestrian 254 movement. The study also brings out the importance of built geometry in enclosing an open 255 space. Varying openness and height of buildings have a high impact on the thermal profile of the 256 enclosed open spaces. With the help of built form, tree cover and surface treatment, the radiant 257 heat and ambient air temperature could be modulated.

258 Numerical models like ENVI-met could be helpful to develop various scenarios to select 259 appropriate built form and surface material for achieving overall desired thermal performance at 260 a different time of the day and year. This study was limited to explore temperature variation in 261 three different ROS. Further, the research scope could be extended to study various other factors 262 that influence thermal comfort in ROS, as well as carry out a sensitivity analysis of each factor.

263 The study successfully brings out key issues that need attention and need to be incorporated in 264 urban planning and design of public spaces, to reduce thermal discomfort in tropical cities and 265 overall urban heat island effect of urban areas.

\section{Acknowledgements}

268 This study is funded by the Ministry of Human Resource Development (MHRD), the 269 Government of India (GoI) project titled CoE-FAST, Grant No. 14MHRD005 and IRCC-IIT 270 Bombay Fund, Grant No. 16IRCC561015. Any opinion, findings and conclusions or 271 recommendations are that of the authors and do not necessarily reflect the views of associated 272 organizations. 


\section{References}

275 Acero, J.A., Herranz-Pascual, K., 2015. A comparison of thermal comfort conditions in four

276 urban spaces by means of measurements and modelling techniques. Build. Environ. 93, 277 245-257. https://doi.org/10.1016/j.buildenv.2015.06.028

278 Akbari, H., Kolokotsa, D., 2016. Three decades of urban heat islands and mitigation technologies 279 research. Energy Build. 133, 834-852. https://doi.org/10.1016/j.enbuild.2016.09.067

280 Bolund, P., Hunhammar, S., 1999. Ecosystem services in urban areas. Ecol. Econ. 29, $293-301$. 281 https://doi.org/10.1016/S0921-8009(99)00013-0

282 Bowler, D.E., Buyung-ali, L., Knight, T.M., Pullin, A.S., 2010. Landscape and Urban Planning 283 Urban greening to cool towns and cities: A systematic review of the empirical evidence. 284 Landsc. Urban Plan. 97, 147-155. https://doi.org/10.1016/j.landurbplan.2010.05.006

285 Chang, C.-R., Li, M.-H., 2014. Effects of urban parks on the local urban thermal environment. 286 Urban For. Urban Green. 13, 672-681. https://doi.org/10.1016/j.ufug.2014.08.001

287 Chatzidimitriou, A., Yannas, S., 2015. Microclimate development in open urban spaces: The 288 influence of form and materials. Energy Build. 108, 156-174.

Crank, P.J., Sailor, D.J., Ban-Weiss, G., Taleghani, M., 2018. Evaluating the ENVI-met microscale model for suitability in analysis of targeted urban heat mitigation strategies. Urban Clim. 26, 188-197. https://doi.org/10.1016/j.uclim.2018.09.002

Emmanuel, R., Johansson, H., E., R., 2007. Urban shading - a design option for the tropics? A study in Colombo, Sri Lanka. Int. J. Climatol. 27, 3-11. https://doi.org/10.1002/joc.1609

Erell, E., Pearlmutter, D., 2012. Effect of high-albedo materials on pedestrian thermal comfort in urban canyons. 8 th Int. Conf. Urban Clim. Dublin .. 8-11. https://doi.org/10.1016/j.uclim.2013.10.005 
Georgi, N.J., Zafiriadis, K., 2006. The impact of park trees on microclimate in urban areas. Urban Ecosyst. 9, 195-209. https://doi.org/10.1007/s11252-006-8590-9

Givoni, B., Noguchi, M., Saaroni, H., Pochter, O., Yaakov, Y., Feller, N., Becker, S., 2003. Outdoor comfort research issues. Energy Build. 35, 77-86. https://doi.org/10.1016/S03787788(02)00082-8

Golasi, I., Salata, F., de Lieto Vollaro, E., Coppi, M., 2018. Complying with the demand of standardization in outdoor thermal comfort: a first approach to the Global Outdoor Comfort Index (GOCI). Build.

Environ.

130

104-119. https://doi.org/10.1016/j.buildenv.2017.12.021

Höppe, P., 1999. The physiological equivalent temperature - a universal index for the biometeorological assessment of the thermal environment. Int. J. Biometeorol. 43, 71-75. https://doi.org/10.1007/s004840050118

Konijnendijk, C.C., Annerstedt, M., Nielsen, A.B., Maruthaveeran, S., 2013. Benefits of Urban Parks - A systematic review, International Federation of Parks and Recreation Administration. Copenhagen and Alnarp.

Lin, W., Yu, T., Chang, X., Wu, W., Zhang, Y., 2015. Calculating cooling extents of green parks using remote sensing: Method and test. Landsc. Urban Plan. 134, 66-75. https://doi.org/10.1016/j.landurbplan.2014.10.012

Lindberg, F., Onomura, S., Grimmond, C.S.B., 2016. Influence of ground surface characteristics on the mean radiant temperature in urban areas. Int. J. Biometeorol. 60, 1439-1452. https://doi.org/10.1007/s00484-016-1135-x

Liu, Y., Li, J., Li, S., 2017. An Evaluation on Urban Green Space System Planning Based on Thermal Environmental Impact. Curr. Urban Stud. 05, 68-81. https://doi.org/10.4236/cus.2017.51005

Martinelli, L., Battisti, A., Matzarakis, A., 2014. Multicriteria analysis model for urban open space renovation: An application for Rome. Sustain. Cities Soc. 14, e10-e20. https://doi.org/10.1016/j.scs.2014.07.002

Mcpherson, E.G., Grimmond, S.U.E., Souch, C., 1997. Quantifying urban forest structure , function, and value : the Chicago Urban Forest Climate Project. Urban Ecosyst. 49-61. 
Mehrotra, S., Bardhan, R., Ramamritham, K., 2020. Diurnal thermal diversity in heterogeneous built area: Mumbai, India. Urban Clim. 100627 https://doi.org/10.1016/j.uclim.2020.100627

Mehrotra, S., Bardhan, R., Ramamritham, K., 2019. Outdoor thermal performance of heterogeneous urban environment:An indicator-based approach for climate-sensitive planning. Sci. Total Environ. https://doi.org/https://doi.org/10.1016/j.scitotenv.2019.03.152

MMR-EIS, 2012. Inventorisation of Open Spaces and Water Bodies in Greater Mumbai.

Noro, M., Busato, F., Lazzarin, R.M., 2015. Urban heat island in Padua, Italy: Experimental and theoretical analysis. Indoor Built Environ. 24, 514-533. https://doi.org/10.1177/1420326X13517404

Salata, F., Golasi, I., de Lieto Vollaro, R., de Lieto Vollaro, A., 2016. Urban microclimate and outdoor thermal comfort. A proper procedure to fit ENVI-met simulation outputs to experimental data. Sustain. Cities Soc. 26, 318-343. https://doi.org/10.1016/j.scs.2016.07.005

Sodoudi, S., Zhang, H., Chi, X., Müller, F., Li, H., 2018. The influence of spatial configuration of green areas on microclimate and thermal comfort Urban Forestry \& Urban Greening The in fl uence of spatial con fi guration of green areas on microclimate and thermal comfort. Urban For. Urban Green. 34, 85-96. https://doi.org/10.1016/j.ufug.2018.06.002

Spronken-Smith, R.A., Oke, T.R., 1998. The thermal regime of urban parks in two cities with different summer climates. Int. J. Remote Sens. 19, 2085-2104. https://doi.org/10.1080/014311698214884

Taleghani, M., 2018. The impact of increasing urban surface albedo on outdoor summer thermal comfort within a university campus. Urban Clim. 24, 175-184. https://doi.org/10.1016/j.uclim.2018.03.001

Tian, Y., Jim, C.Y., Wang, H., 2014. Assessing the landscape and ecological quality of urban green spaces in a compact city. Landsc. Urban Plan. 121, 97-108. https://doi.org/10.1016/j.landurbplan.2013.10.001

Wu, Z., Chen, L., 2017. Optimizing the spatial arrangement of trees in residential neighborhoods for better cooling effects : Integrating modeling with in-situ measurements Landscape and 

Urban Planning Optimizing the spatial arrangement of trees in residential neighborhoods for . Landsc. Urban Plan. 167, 463-472. https://doi.org/10.1016/j.landurbplan.2017.07.015

361 Zhang, B., Xie, G., Gao, J., Yang, Y., 2014. The cooling effect of urban green spaces as a 362 contribution to energy-saving and emission-reduction: A case study in Beijing, China. 363 Build. Environ. 76, 37-43. https://doi.org/10.1016/j.buildenv.2014.03.003 